\title{
Absent ileocecal valve predicts the need for repeated step in children
}

\section{Wester, Tomas}

2017-03

Wester, T , Lilja , H E , Stenstrom , P \& Pakarinen, M 2017 , ' Absent ileocecal valve

predicts the need for repeated step in children ' , Surgery , vol. 161 , no. 3 , pp. 818-822 . https://doi.org/10.1016/j.su

http://hdl.handle.net/10138/234620

https://doi.org/10.1016/j.surg.2016.09.011

publishedVersion

Downloaded from Helda, University of Helsinki institutional repository.

This is an electronic reprint of the original article.

This reprint may differ from the original in pagination and typographic detail.

Please cite the original version. 


\title{
Pediatric surgery
}

\section{Absent ileocecal valve predicts the need for repeated step in children}

Tomas Wester, MD, PhD, ${ }^{\mathrm{a}}$ Helene Engstrand Lilja, MD, PhD, ${ }^{\mathbf{b}}$ Pernilla Stenström, MD, PhD, ${ }^{\mathbf{c}}$ and Mikko Pakarinen, MD, PhD, ${ }^{\mathbf{d}}$ Stockholm, Uppsala, and Lund, Sweden, and Helsinki, Finland

\begin{abstract}
Background. Serial transverse enteroplasty facilitates weaning from parenteral support in selected patients with short bowel syndrome, although repeated procedure is frequently required. Our aim was to evaluate the outcome of a series of patients after serial transverse enteroplasty and define predictors of repeated serial transverse enteroplasty and weaning off parenteral support.

Methods. All children who underwent serial transverse enteroplasty at 4 Nordic pediatric surgery centers from 2004-2015 were included in this observational study. Data were collected from the patient records. The study was approved by the local ethics review boards.

Results. Twenty-seven children with short bowel with initial median small bowel length of $26 \mathrm{~cm}$ (range, 10-100 cm) were included. Eleven patients had the ileocecal valve remaining. Serial transverse enteroplasty was performed at median age of 7.5 months (range, 0.9-224 months). Serial transverse enteroplasty made the small bowel $46 \%$ (0-233\%) longer. Eleven patients (41\%) underwent a repeated serial transverse enteroplasty 12 months (1.0-72 months) later; 7 patients required additional operative procedures, but none were transplanted. At follow-up, 45.1 months (1.8-126 months) after the first serial transverse enteroplasty, 11 (41\%) patients needed parenteral support. The remaining 16 patients had been weaned off parenteral support. One patient had died. Absence of the ileocecal valve was the only factor, which predicted the need for a repeated serial transverse enteroplasty (odds ratio 16.7, 95\% confidence interval, 1.7-164.8, $\mathrm{P}=.007)$. No factor was identified predicting need for parenteral support at follow-up.

Conclusion. A majority of children with short bowel syndrome can be weaned from parenteral support after serial transverse enteroplasty. The absence of the ileocecal valve predicts the need for a repeated serial transverse enteroplasty, which was required by $40 \%$ of the patients. (Surgery 2017;161:818-22.)

From the Unit of Pediatric Surgery, ${ }^{a}$ Department of Women's and Children's Health, Karolinska University Hospital, and Karolinska Institutet, Stockholm; Unit of Pediatric Surgery, ${ }^{b}$ Department of Women's and Children's Health, University Children's Hospital, Uppsala; Department of Pediatric Surgery, ${ }^{c}$ Skäne University Hospital, Lund, Sweden; and Pediatric Surgery, ${ }^{d}$ Pediatric Liver and Gut Research Group, Children's Hospital, Helsinki University Hospital, Helsinki, Finland
\end{abstract}

INTESTINAL FAILURE in children is associated with significant morbidity and mortality. Short bowel syndrome is the most common cause of pediatric

Supported by Her Royal Highness Crown Princess Lovisa's Foundation.

Accepted for publication September 12, 2016.

Reprint requests: Tomas Wester, MD, PhD, Department of Pediatric Surgery, Karolinska University Hospital, Q3:03, Solna, Stockholm SE-171 76, Sweden. E-mail: tomas.wester@ karolinska.se.

0039-6060/\$ - see front matter

(c) 2016 Elsevier Inc. All rights reserved.

http://dx.doi.org/10.1016/j.surg.2016.09.011 intestinal failure. The main causes of neonatal short bowel are necrotizing enterocolitis, intestinal atresia, gastroschisis, and malrotation with volvulus. ${ }^{1,2}$ Adaptation-associated bowel dilatation often presents with increasing feeding intolerance, which precludes weaning from parenteral support. This, in addition to symptoms of intestinal bacterial overgrowth and dysmotility such as diarrhea, vomiting, and/or D-lactic acidosis, is an indication to consider operative management. ${ }^{3,4}$ Autologous intestinal reconstruction by a longitudinal intestinal lengthening and tapering procedure was first described by Bianchi et $\mathrm{al}^{5}$ in 1980. More recently, 
serial transverse enteroplasty (STEP), a technically less challenging procedure, was introduced in 2003. ${ }^{6,7}$ STEP has been shown to facilitate weaning from parenteral support in selected patients with short bowel syndrome, although repeated procedure is frequently required. ${ }^{8}$ Factors that predict the need for repeated STEP and weaning off parenteral support have not been well characterized.

The aim of this study was to evaluate the outcomes of a series of patients after STEP and define predictors of repeated STEP and need for parenteral support at follow-up.

\section{METHODS}

This cross-sectional, observational study was approved by the local ethics review boards. After informed consent was provided, all children who underwent STEP at 4 Nordic pediatric surgery centers from 2004-2015 were included. Data were collected retrospectively from the patient records. The recorded variables were sex, gestational age, birth weight, birth height, cause of short bowel, initial small bowel length, absence of the ileocecal valve, and number of laparotomies before STEP. Data on indication for STEP and repeated STEP, weight and height before STEP, total small bowel length before and after the reconstruction, maximal bowel width at STEP and repeated STEP, and number of stapler firings also were collected. Number of parenteral support infusions and the ratio of enteral/total caloric intake before STEP and at follow-up were registered. The date when full enteral autonomy was achieved was recorded. $\mathrm{Z}$ scores for weight and height as well as serum bilirubin and liver enzyme levels before STEP and at follow-up were compared. Sex, gestational age, cause of short bowel, initial small bowel length, and absence of ileocecal valve were analyzed as potential predictive risk factors for the need for repeated STEP. The ability of sex, gestational age, cause of short bowel, initial small bowel length, and absence of ileocecal valve, in addition to repeated STEP, to predict need for parenteral support at follow-up was analyzed.

Statistics. Categorical data are presented as frequencies and continuous data as median (range). For potential predictive factors, odds ratios with $95 \%$ confidence intervals were calculated, and Fisher exact test was used for further analysis. Data on gestational age ( $\leq 34$ weeks; $>34$ weeks) and initial small bowel length $(\leq 30 \mathrm{~cm} ;>30 \mathrm{~cm})$ were categorized. The sample size and the number of events were considered too small for multivariable analysis. Wilcoxon signedrank test was used to compare bowel length before and after STEP as well as levels of bilirubin and liver enzymes, z scores for weight and height, and enteral tolerance before STEP and at follow-up. Statistical analysis was carried out with SPSS version 22.0 software (IBM, Armonk, NY).

\section{RESULTS}

Twenty-seven children with short bowel, 13 girls and 14 boys, who underwent 39 STEP procedures were included. The median gestational age was 34 weeks (23-40 weeks). The median birth weight was 2,356 g (495-3,900 g), and birth height was $45 \mathrm{~cm}(28-54 \mathrm{~cm})$. The cause of short bowel was small bowel atresia $(n=18)$, volvulus $(n=6)$, gastroschisis $(n=7)$, and necrotizing enterocolitis $(n=4)$. In some cases $>1$ underlying condition was encountered. The initial median small bowel length was $26 \mathrm{~cm}(10-100 \mathrm{~cm})$. The patients had undergone 2 (1-10) laparotomies before STEP. All patients depended on parenteral support before STEP. The median number of weekly parenteral support infusions was 7 (2-7). The median ratio of enteral/total caloric intake was $0.24(0-0.84)$. Before STEP 17 patients had symptoms of bacterial overgrowth, 14 had culture-verified septicemia, 16 were dependent on enteral antibiotics, and 15 had fluid and electrolyte disturbances.

STEP. The indication for STEP was adaptationassociated bowel dilatation in combination with symptoms and findings shown in Table I. STEP was performed as previously described ${ }^{2,8}$ at median age of 7.5 months (0.9-224 months). The median body weight at STEP was $6.5 \mathrm{~kg}(3.7-34.0 \mathrm{~kg})$, and height was $63 \mathrm{~cm}(52-163 \mathrm{~cm})$. Eleven patients $(41 \%)$ had the ileocecal valve remaining. The median total small bowel length before STEP was $54 \mathrm{~cm}(15-93 \mathrm{~cm})$, and the median total small bowel length after STEP was $71 \mathrm{~cm}(27-150 \mathrm{~cm} ; P<.001)$. The median maximal small bowel width was $5 \mathrm{~cm} \cdot{ }^{2-8}$ A median number of 9 stapler firings (2-25) were used for the reconstruction. STEP made the small bowel $46 \%(0-233 \%)$ longer. At the time of STEP 3 patients underwent an additional segmental tapering enteroplasty, 3 underwent strictureplasty, 2 bowel resections, and 8 underwent other additional procedures (significant adhesiolysis, gastrostomy, revision of anastomosis, or stoma closure). Early complications included bleeding $(n=1)$, leakage $(n=1)$, fascia rupture $(n=2)$, thrombosis/endocarditis $(n=1)$, and septicemia $(n=1)$.

Repeated STEP. Eleven patients $(41 \%)$ underwent repeat STEP 12 months (1.0-72 months) after initial STEP. The indication for repeat STEP was symptoms and findings shown in Table I. Six patients (54\%) who underwent repeated STEP 
Table I. Indications for initial STEP and repeat STEP

\begin{tabular}{lcc}
\hline & $\begin{array}{c}\text { Initial } \\
\text { STEP } \\
(\mathrm{n}=27)\end{array}$ & $\begin{array}{c}\text { Repeat } \\
\text { STEP } \\
(\mathrm{n}=11)\end{array}$ \\
\hline Inability to increase & 25 & 8 \\
$\quad$ enteral intake & & \\
Dysmotility & 21 & 7 \\
Vomiting & 17 & 5 \\
Bacterial overgrowth & 15 & 8 \\
Fluid and electrolyte & 13 & 4 \\
$\quad$ problems & 9 & 3 \\
Obstructive symptoms & 5 & 5 \\
Increased secretions & 3 & 0 \\
Intestinal failure-associated & & \\
$\quad$ liver disease & 3 & 2 \\
D-lactic acidosis & 0 & 7 \\
Vascular access problems & Not applicable & 7 \\
Redilatation & & \\
\hline
\end{tabular}

were dependent on antibiotics. The median body weight before repeated STEP was $11.4 \mathrm{~kg}$ $(6.5-33.0 \mathrm{~kg})$ and median height was $83 \mathrm{~cm}$ $(60-163 \mathrm{~cm})$. The median total small bowel length before repeated STEP was $90 \mathrm{~cm}(54-150 \mathrm{~cm})$ and after the reconstruction $101 \mathrm{~cm} \quad(60-180 \mathrm{~cm}$; $P=.005)$. A median of 12 stapler firings (2-22) were used. Three patients underwent concomitant segmental tapering enteroplasty and one underwent strictureplasty. There were no early complications after repeat STEP.

Additional procedures. Seven patients required further operative procedures: small bowel resection $(n=2)$, tapering $(n=2)$, gastrostomy $(n=1)$, and a third STEP $(n=1)$. No patient needed small bowel transplantation. One of the patients underwent a limited small bowel resection twice due to chronic small bowel ulcers causing irondeficiency anemia and hypoalbuminemia.

Outcomes. At follow-up, 45.1 months (1.8126.0 months) after the first STEP and 12.8 months (1.8-80.0 months) after repeated STEP, 11 (41\%) patients required parenteral support. The remaining $16(59 \%)$ patients had been completely weaned from parenteral support 16.5 months after first STEP (0.7-109.2). Six (55\%) of 11 patients who had undergone repeated STEP had been weaned from parenteral support compared with $10(62 \%)$ of 16 patients who had only undergone one STEP $(P=.710)$. Three of 7 patients who had small bowel redilatation when they underwent repeated STEP had been weaned off parenteral support. The 11 patients on parenteral support at follow-up needed 7 parenteral infusions per week (3.5-7 weeks) and the median enteral caloric intake/total caloric intake ratio was $0.63(0.42-0.90)$ compared with $0.27(0.06-0.83)$ before STEP $(P=.004)$. The median $\mathrm{z}$ score for weight before STEP was -1.24 $(-4.98$ to 0.71$)$ and at follow-up $-0.89(-4.08$ to $1.15 ; P=1.00)$. The median $\mathrm{z}$ score for height before STEP was -1.18 ( -6.23 to 0.78$)$ and at follow-up $-1.11(-3.65$ to $1.34 ; P=.29)$. Seven patients depended on continuous enteral antibiotics, 6 had had culture-verified septicemia, 7 had symptoms indicating bacterial overgrowth, 3 were vomiting, and 5 had diarrhea causing electrolyte disturbances. In 5 patients redilatation of the small bowel was observed, 3 of who had undergone a repeated STEP. One patient had died due to an Abernethy malformation and septicemia.

Bilirubin and liver enzyme levels before STEP and at follow-up are shown in Table II. Six patients had total bilirubin $>20 \mu \mathrm{mol} / \mathrm{L}$ before STEP compared with 1 at follow-up.

Predictive factors needed for repeated STEP. The analysis of potential predictive factors for repeated STEP is shown in Table III. Absence of the ileocecal valve was the only factor that predicted the need for a repeated STEP (odds ratio $16.7,95 \%$ confidence interval, $1.7-164.8, P=.007)$.

Predictive factors for enteral autonomy at follow-up. The analysis of potential predictive factors for need for parenteral nutrition at follow-up is shown in Table IV. No risk factor could be identified predicting need for parenteral support at follow-up.

\section{DISCUSSION}

This series of 27 children with short bowel and intestinal failure managed with STEP at 4 Nordic pediatric surgery centers is one of the largest in the literature. Most previous studies originate from major North American centers. In the present study repeated STEP was required by $41 \%$ of the patients, while $59 \%$ of the patients had been weaned off parenteral support by a median time of 16.5 months after STEP. Among the patients who remained dependent on parenteral support after STEP, parenteral energy requirement reduced significantly. It has been reported that $33-88 \%$ of patients can be weaned off parenteral support after STEP. ${ }^{4,8-15}$ The patients who had undergone repeated STEP had a similar chance to be weaned off parenteral support compared with those who underwent only one STEP supporting active operative approach to redilatation. There were no significant differences between weight and height $\mathrm{z}$ scores before STEP and at follow-up. Javid et $\mathrm{al}^{14}$ showed that weight-for-age $\mathrm{z}$ score had increased at follow-up, whereas heightfor-age $\mathrm{z}$ score did not change significantly. Mercer 
Table II. Total bilirubin, conjugated bilirubin, ASAT, and ALAT before STEP and at follow-up

\begin{tabular}{lccc}
\hline & Before STEP & At follow-up & P value \\
\hline Total bilirubin, $\mu \mathrm{mol} / \mathrm{L}$ & $8.5(2-242)$ & $4(2-26)$ & .017 \\
Conjugated bilirubin, $\mu \mathrm{mol} / \mathrm{L}$ & $3.95(1-185)$ & $2(2-8)$ & .064 \\
ASAT, $\mu \mathrm{kat} / \mathrm{L}$ & $0.85(0.37-10.0)$ & $0.60(0.40-4.02)$ & .115 \\
ALAT, $\mu \mathrm{kat} / \mathrm{L}$ & $0.665(0.19-3.4)$ & $0.47(0.28-3.06)$ & .527 \\
\hline
\end{tabular}

*Wilcoxon signed-rank test.

ASAT, Aspartate aminotransferase; ALAT, alanine aminotransferase.

Table III. Predictive factors for the need of repeated STEP

\begin{tabular}{|c|c|c|c|}
\hline Predictive factor & $\mathrm{n}$ & OR $(95 \%$ CI $)$ & $\mathrm{P}$ value* \\
\hline \multicolumn{4}{|l|}{ Sex } \\
\hline Male & $6 / 11$ & $1.20(0.26-5.59)$ & 1.00 \\
\hline Female & $5 / 11$ & 1 & \\
\hline \multicolumn{4}{|l|}{ Gestational age } \\
\hline$\leq 34$ wk & $8 / 11$ & $2.67(0.51-13.88)$ & .43 \\
\hline$>34 \mathrm{wk}$ & $3 / 11$ & 1 & \\
\hline \multicolumn{4}{|c|}{ Cause of short bowel } \\
\hline Bowel atresia & $7 / 11$ & $0.80(0.16-4.02)$ & 1.00 \\
\hline Volvulus & $2 / 11$ & $0.67(0.10-4.48)$ & 1.00 \\
\hline Gastroschisis & $5 / 11$ & $5.83(0.87-38.9)$ & .084 \\
\hline NEC & $2 / 11$ & $1.56(0.18-13.11)$ & 1.00 \\
\hline \multicolumn{4}{|c|}{ Initial small bowel length } \\
\hline$\leq 30 \mathrm{~cm}$ & $7 / 11$ & $0.58(0.11-3.10)$ & .68 \\
\hline$>30 \mathrm{~cm}$ & $4 / 11$ & 1 & \\
\hline \multicolumn{4}{|c|}{ Absent ileocecal valve } \\
\hline Yes & $10 / 11$ & $16.67(1.69-164.8)$ & .008 \\
\hline No & $1 / 11$ & 1 & \\
\hline
\end{tabular}

*Fisher exact test.

In total, 11 patients underwent repeated STEP. Odds ratio with $95 \%$ confidence interval (CI) was calculated.

$N E C$, Necrotizing enterocolitis.

et $\mathrm{al}^{4}$ showed that height and weight $\mathrm{z}$ scores gradually increased during the first year after STEP. The increase in z score for weight became statistically significant 1 year after STEP. In the present study, operative and early postoperative complications were few, as expected from previous reports. ${ }^{4}$ Also, liver enzymes and bilirubin had improved at follow-up compared with before STEP. Mortality was low, and the death in this series was not related to the STEP procedure.

One aim of this study was to define predictive factors of the need for repeated STEP and need for parenteral nutrition at follow-up. We choose to analyze whether sex, gestational age, cause of short bowel, initial small bowel length, and absent ileocecal valve could predict the need for repeated STEP. Absent ileocecal valve was the only factor that predicted the need for repeated STEP. The ileocecal region is the sole source of various enterohormones regulating intestinal motility, growth, and absorptive function with unique
Table IV. Predictive factors for parenteral support at follow-up

\begin{tabular}{|c|c|c|c|}
\hline Predictive factor & $\mathrm{n}$ & OR & $\mathrm{P}$ value ${ }^{*}$ \\
\hline \multicolumn{4}{|l|}{ Sex } \\
\hline Male & $6 / 11$ & $1.20(0.26-5.59)$ & 1.00 \\
\hline Female & $5 / 11$ & 1 & \\
\hline \multicolumn{4}{|l|}{ Gestational age } \\
\hline$\leq 34 \mathrm{wk}$ & $8 / 11$ & $2.67(0.51-13.88)$ & .43 \\
\hline$>34 \mathrm{wk}$ & $3 / 11$ & 1 & \\
\hline \multicolumn{4}{|c|}{ Cause of short bowel } \\
\hline Bowel atresia & $6 / 11$ & $0.40(0.08-2.06)$ & .41 \\
\hline Volvulus & $2 / 11$ & $0.67(0.10-4.48)$ & 1.00 \\
\hline Gastroschisis & $3 / 11$ & $1.12(0.20-6.43)$ & 1.00 \\
\hline NEC & $3 / 11$ & $5.62(0.50-63.28)$ & .27 \\
\hline \multicolumn{4}{|c|}{ Initial small bowel length } \\
\hline$\leq 30 \mathrm{~cm}$ & $9 / 11$ & $2.70(0.43-16.94)$ & .40 \\
\hline$>30 \mathrm{~cm}$ & $2 / 11$ & 1 & \\
\hline $\begin{array}{l}\text { Absent ileocecal } \\
\text { valve }\end{array}$ & $8 / 11$ & $2.67(0.51-13.88)$ & .43 \\
\hline Ileocecal valve & $3 / 11$ & 1 & \\
\hline \multicolumn{4}{|l|}{ Repeated STEP } \\
\hline Yes & $5 / 11$ & $1.39(0.29-6.61)$ & .71 \\
\hline No & $6 / 11$ & 1 & \\
\hline
\end{tabular}

functional properties, which may explain this finding. Although redilatation represents one of the main complications of STEP occurring in 30$40 \%$ of the patients, predictive factors for repeated STEP have not been well characterized previously.

Most previous studies have focused on feasibility and enteral autonomy. We also analyzed if sex, gestational age, cause of short bowel, initial small bowel length, absent ileocecal valve, and repeated STEP predicted need for parenteral support at follow-up. None of these factors predicted need for parenteral support. It has been shown previously, in a large cohort of children with intestinal failure, that longer bowel length, preserved ileocecal valve, and underlying NEC was associated with weaning off parenteral support. ${ }^{16}$ It was shown recently that excessive small bowel dilatation in contrast series, both measured as absolute terms and as ratio between maximal small bowel width and the height 
of the fifth lumbar vertebra, predicted weaning from parenteral support as well as survival. ${ }^{17}$ Previous data indicate that children who experience redilatation after STEP had worse prognosis and were less likely to be weaned off parenteral nutrition. ${ }^{18,19}$ We could not analyze small bowel diameter ratio systematically in this group of patients as contrast studies had not been performed routinely in all children. It is interesting that absence of the ileocecal valve predicted the need for repeat STEP, but not ultimately the ability to wean off parenteral support. This difference could be explained by the small sample size. It also is possible that parameters not analyzed in this study, such as remaining length of ileum, colonic length, and small bowel diameter, are important.

The 2 main limitations of this study were the lack of controls and a relatively small sample size. Ideally, a randomized, controlled trial comparing serial transverse enteroplasty with conservative treatment would be undertaken. This would make it easier to define indications for STEP and also ascertain longterm effects. However, such a trial would be ethically very difficult to undertake. Pakarinen et $\mathrm{al}^{13}$ showed retrospectively that children with short bowel syndrome had similar mortality rate and parenteral support dependency at 4 years with or without an autologous intestinal reconstruction. The small sample size in our study makes it likely that type 2 errors could influence the analysis of predictive factors. Also, the low number of events, repeated STEP, and weaning off parenteral support was too low for multivariable analysis, which would have been preferable. Another limitation of the study was that there were no predetermined clinical set of circumstances that would lead to repeat STEP. The decision to repeat STEP was made by the individual surgeon.

In conclusion, a majority of children with short bowel syndrome can be weaned off parenteral support after STEP. The absence of the ileocecal valve predicts the need for repeated STEP, which was required by $41 \%$ of the patients. Whenever possible, the ileocecal valve should be preserved. However, this is often not an option because the ileocecal valve is absent at birth or the bowel is virtually necrotic and resection unavoidable. Chances for weaning off parenteral support and survival were similar after the first and repeated STEP.

\section{REFERENCES}

1. Gutierrez IM, Kang KH, Jaksic T. Neonatal short bowel syndrome. Semin Fetal Neonatal Med 2011;16:157-63.
2. Pakarinen MP. Autologous intestinal reconstruction surgery as part of comprehensive management of intestinal failure. Pediatr Surg Int 2015;31:453-64.

3. Merras-Salmio L, Pakarinen MP. Refined multidisciplinary protocol-based approach to short bowel syndrome improves outcomes. J Pediatr Gastroenterol Nutr 2015;50:289-92.

4. Mercer DF, Hobson BD, Gerhardt BK, Grant WJ, Vargas LM, Langnas AN, et al. Serial transverse enteroplasty allows children with short bowel to wean from parenteral nutrition. J Pediatr 2014;164:93-8.

5. Bianchi A. Interstinal loop lengthening-a technique for increasing small bowel length. J Pediatr Surg 1980;15: 145-51.

6. Kim HB, Fauza D, Garza J, Oh JT, Nurko S, Jaksic T. Serial transverse enteroplasty (STEP): a novel bowel lengthening procedure. J Pediatr Surg 2003;38:425-9.

7. Kim HB, Lee PW, Garza J, Duggan C, Fauza D, Jaksic T. Serial transverse enteroplasty for short bowel syndrome: a case report. J Pediatr Surg 2003;38:881-5.

8. Wester T, Borg H, Naji H, Stenström P, Westbacke G, Lilja HE. Serial transverse enteroplasty to facilitate enteral autonomy in selected children with short bowel syndrome. Br J Surg 2014;101:1329-33.

9. Jones BA, Hull MA, Potanos KM, Zurakowski D, Fitzgibbons SC, Ching A, et al. Report of 111 consecutive patients enrolled in the International Serial Transverse Enteroplasty (STEP) Data Registry: a retrospective observational study. J Am Coll Surg 2013;216:438-46.

10. Wales PW, de Silva N, Langer JC, Fecteau A. Intermediate outcomes after serial transverse enteroplasty in children with short bowel syndrome. J Pediatr Surg 2007;42:1804-10.

11. Ching YA, Fitzgibbons S, Valim C, Zhou J, Duggan C, Jaksic T, et al. Long-term nutritional and clinical outcomes after serial transeverse enteroplasty at a single institution. J Pediatr Surg 2009;44:939-43.

12. Oliveira C, de Silva N, Wales PW. Five-year outcomes after serial transverse enteroplasty in children with short bowel syndrome. J Pediatr Surg 2012;47:931-7.

13. Pakarinen MP, Kurvinen A, Koivusalo AI, Iber T, Rintala RJ. Long-term controlled outcomes after autologous intestinal reconstruction surgery in treatment of severe short bowel syndrome. J Pediatr Surg 2013;48:339-44.

14. Javid PJ, Sanchez SE, Horslen SP, Healey PJ. Intestinal lengthening and nutritional outcomes in children with short bowel syndrome. Am J Surg 2013;205:576-80.

15. Oh PS, Fingerat AL, Shah MY, Ventura KA, Brodie S, Ovichinsky N, et al. Improved tolerance for enteral nutrition after serial transverse enteroplasty (STEP) in infants and children with short bowel syndrome-a seven-year single-center experience. J Pediatr Surg 2014;49:1589-92.

16. Khan FA, Squires RH, Litman HJ, Balint J, Carter BA, Fisher JG, et al. Predictors of enteral autonomy in children with intestinal failure: a multicenter cohort study. J Pediatr 2015;167:29-34.

17. Hukkinen M, Kivisaari R, Merras-Salmio L, Koivusalo A, Pakarinen MP. Small bowel dilatation predicts prolonged parenteral nutrition and decreased survival in pediatric short bowel syndrome. Ann Surg 2016. [Epub ahead of print].

18. Kang KH-J, Gutierrez IM, Zurakowski D, Di Perna S, Buonomo C, Kim HB, et al. Bowel re-dilatation following serial transverse enteroplasty (STEP). Pediatr Surg Int 2012; 28:1189-93.

19. Miyasaka EA, Brown PI, Teitelbaum DH. Redilatation of bowel after intestinal lengthening procedures-a indicator for poor outcome. J Pediatr Surg 2011;46:145-9. 